\title{
Physical activity engagement after breast cancer: Advancing the health of survivors
}

\author{
S. Y. Loh $^{1 \#}$, S. L. Chew ${ }^{1}$, K. F. Quek ${ }^{2}$ \\ ${ }^{1}$ Department of Rehabilitation, Faculty of Medicine, University of Malaya, Kuala Lumpur, Malaysia; \\ ${ }^{\#}$ Corresponding Author: syloh@um.edu.my \\ ${ }^{2}$ School of Medicine and Health Sciences, Monash University, Sunway, Malaysia
}

Received 15 January 2013; revised 25 February 2013; accepted 7 March 2013

Copyright (C) 2013 S. Y. Loh et al. This is an open access article distributed under the Creative Commons Attribution License, which permits unrestricted use, distribution, and reproduction in any medium, provided the original work is properly cited.

\begin{abstract}
Background: Physical inactivity is identified as the fourth leading risk factor for global mortality and associated with increased breast cancer diagnosis and risks of recurrence. Objectives: To investigate the level of physical activity engagement after breast cancer in survivors and healthy controls. Design: A descriptive casecontrol study on survivors and matched (ethnic, gender, age) healthy controls was surveyed using a pre-post questionnaire and a 1-minute cancer control media. The socio- and medical demographic data, physical activity status information were obtained from self report questionnaires. Results: Breast cancer survivors $(n=51)$ were found to participate in low-moderate level of physical activity while healthy controls $(n=45)$ participated in moderate-vigorous level of physical activity. Healthy adults reported more barriers and excuses but all participants (90\% survivors and control) were unaware of the strong inverse relationship between level of physical activity and risks of cancer recurrence. The post test on video showed an increased awareness and intention to re-engagement in physical activity for cancer control $(M=7.1 \pm 1.53, p<0.01)$. Conclusion: The finding suggests that simple public health message within the Model of cancer survivorship care must be disseminated. The "teachable moments" after a cancer diagnosis should be optimised to promote rehabilitation for physically active lifestyle.
\end{abstract}

Keywords: Cancer Control; Physical Activity;

"S. Y. Loh study design, analysis and manuscript; S. L. Chew analysis and manuscript; K. F. Quek analysis.
Breast Cancer; Public Health; Rehabilitation

\section{INTRODUCTION}

Being physically active can prevent the occurrences of many chronic diseases including cardiovascular accidents [1], type 2 diabetes [2], obesity [3], and osteoporosis [4], but also prevent a cancer recurrence and improve the overall quality of life $[5,6]$. An increasing research evidence demonstrates that being physically active can reduce cancer risks, especially for colorectal cancer [7], breast cancer [8], endometrial cancer [9], lung cancer [10] and prostate cancer [11]. The current concluding evidence for physical activity is reported as convincing for reducing colon and breast cancers, probable for prostate, possible for lung and endometrial cancers and insufficient for cancers at all other sites [12].

Advancing health of survivors via physical activity engagement is an attainable strategy in cancer control, even though the exact mechanism of how physical activity directly benefits some cancer survivors is not known. However, for breast cancer, physical activity lowers the risk of cancer by affecting the level of hormonal concentrations and energy balance [13]. Thune et al. [14] offered that by caloric restriction, the propagated activity of the mammary glands is reduced and will thereby inhibit the carcinogenesis process in the breast. Researchers are also examining the relationship between activity and the biomarker C-reactive protein (a chronic lowgrade inflammation, as a possible risk factor for cancer). The Alberta Physical Activity and Breast Cancer Prevention (ALPHA) Trial found that a 1-year moderateto-vigorous aerobic exercise trial in healthy postmenopausal women, showed a decline in the biomarker Creactive protein [15].

Research evidence also suggests that the effect of physical activity varies across the subgroups of breast cancer and across the illness trajectory. Being overweight 
at the time of breast cancer diagnosis [16,17], and weight gain after diagnosis [18] are associated with poorer survival.

With particular reference to dose-response of activity and breast cancer, a trend analysis showed a $6 \%(3 \%$ $8 \% ; 95 \% \mathrm{CI})$ decrease in breast cancer risk for each additional hour of physical activity per week assuming that the level of activity would be sustained [19]. The Nurse Health Study which assessed leisure time physical activity on 2296 women, concluded that even modest amounts of physical activity after a breast cancer diagnosis promote survival [20] particularly for those with stage I, II and III cancer. Adjusted for stage of disease, the relative risk of death from breast cancer decreased with all level of physical activity compared with being sedentary. The risk of death from breast cancer was 19 percent less (among women who undertook 180 - 534 met-min- utes/ week of exercise); 54 percent less (for 540 - 894 metminutes/week); 42 percent less (for 900 - 1434 metminutes/week); and 29 percent less (for 1440 or more met-minutes/week) of recreational exercise. a large systematic review (19 cohort and 29 case-control studies) found a strong inverse association between physical activity and postmenopausal breast cancer with risk reductions ranging from $20 \%$ up to to $80 \%$ [21].

WHO recommended 30 minutes per day of moderate level activity for $\geq 5$ days a week, or 20 minutes of vigorous activity for $\geq 3$ days per week (centre for disease, 2003). With cancer, this weekly dosage may even be higher, but it appears that even the WHO's dosage is challenging for most people, including healthy people. In fact, an alarming $60 \%$ adults worldwide are classified as inactive [22]. Despite the strong evidence, inactivity or sedentary lifestyle is on the steep rise, across adults in the world, especially in women, older age and urban residence. Multiple factors such as an increase urbanization, neighbourhood level violence [23], high-density traffic [24], air pollution [25], lack of recreation facilities [26] and demanding occupations have contributed to this low participation in everyday physical activity. In USA, a high $74 \%$ of American cannot meet this recommended amount of physical activity [27]. In Malaysia, a population-based household survey of adults $(\mathrm{n}=339,333)$ found that the prevalence of overall physical inactivity was amongst almost half the Malaysian adult population $(43.7 \%)$, and the prevalence of inactivity was higher in sub domains of working time $(72.6 \%)$, travel time $(72.1 \%)$ and leisure time (85.7\%) [28]. The health risk of physical inactivity contributes to an estimated of 3.2 million deaths globally [29].

With 1.1 million women worldwide diagnosed with breast cancer and 410,000 die from it each year [30], physical activity can be promoted as cancer control strategy as it is inversely related to weight gain during survival [31]. However, most of our multiethnic breast cancer survivors complained of inadequate information and unawareness [32,33], including for physical activity engagement. Therefore, to enhance rehabilitation of breast cancer survivors, a better understanding of how intervention works [34], and how women perceived the need to engage in activity is needed. The aim of this study is to explore women's perception as well as the correlates of the physical activity amongst the multiethnic women. The objectives are to investigate the behavioral pattern, self-efficacy and perceived barriers to physical activity in women with breast cancer and in comparison with healthy women. The use of the video clip to create awareness on the importance of physical activity for cancer survivors will be used in this pre-post survey.

\section{METHODS}

\subsection{Design and Setting}

This survey was conducted in University Malaysia Medical Centre (UMMC). The ethical approval for this study was obtained from the University Malaya Medical Centre Ethical Committee.

\subsection{Subjects}

The breast cancer survivors subjects were obtained through an introductory session of an Active Lifestyle program organised in University Malaya Medical Centre while the healthy volunteers/controls were recruited through online survey. Informed consent was obtained before the subjects were asked to complete the questionnaire. From the database of those diagnosed with breast cancer between 2005 and 2010, women with breast cancer who were randomly selected, 51 subjects consented to participate. Healthy volunteers were recruited through convenience sampling method, and via facebook and email modes, to reach women that matched the gender, ethnicity, marital status and age ( \pm 3 years) of the breast cancer survivors.

\subsection{Tools}

A questionnaire to gather the socio-medical demographic data, pre-diagnosis physical activity, current physical activity (International Physical Activity Questionnaire), barriers to physical activity, exercise selfefficacy and awareness of physical activity guidelines for cancer were collated. A video pertaining to guidelines of physical activity and advantages of physical activity to cancer was presented to participants, who were assessed on awareness and knowledge of guidelines and benefits of physical activity at pre- and post-viewing. 


\subsection{International Physical Activity Questionnaire-Short Form (IPAQ)}

A self report physical activity tool for measuring physical activity in 15 - 69 years old adults [35]. It assesses several domains, the specific types of activity (walking, moderate-intensity activities and vigorous intensity activities); frequency (in days per week) and duration (time per day). Computation of Total daily PA (MET-min $\cdot$ day $^{-1}$ ) is by summing the product of reported time within each item by each category-defined MET value (3.3 METs, 4.0 METs and 8.0 METs index for walking, moderate and vigorous) and expressed as a daily average MET score. MET is metabolic equivalent whereby 1 MET equal the resting energy expenditure, according to the IPAQ scoring protocol

(www.ipaq.ki.se).

\subsection{Exercise Self-Efficacy Scale}

The exercise self-efficacy scale is a measure of people's confidence in their capabilities to attain regular exercise. The 18-item scale using self rating scores 0 100 ("cannot do at all", 50 being "moderately certain can do" and 100 as "highly certain can do"), was developed by Bandura [36]. Factor analysis showed three sub-factors: 1) situational/interpersonal factor, 2) competing demands factor, and 3) internal feelings factor [37].

\subsection{Statistical Analysis}

Data was analysed using SPSS version 17. Descriptive analyses were conducted to describe the total energy expenditure, self-efficacy for exercise, and barriers to regular physical activity. Statistical analyses such as the chi-square test, Fisher's Exact Test, Mann Whitney U Test, ANOVA or Kruskal Wallis were employed where necessary with $\mathrm{p}<0.05$ was taken as a level of significant. Missing values will be substituted with mean score.

\section{RESULT}

\subsection{Demographic}

Table 1 summarises the socio- demographic characteristics and medical background of the 51 breast cancer (BC) survivors and 45 healthy controls (HC). The cancer subjects were mainly Chinese, followed closely by Indians and Malays. Their age ranged from 31 to 63 years old (mean of $49.12 \pm 8.86$ ). The body mass index (BMI) for $\mathrm{BC}$ ranged between 18.3 and 33.3. BC was diagnosed for at least nine months to as long as 83 months. Most of the participants were married $(\mathrm{n}=77)$, had secondary education $(\mathrm{n}=41)$, post-menopause $(\mathrm{n}=51)$ and most $\mathrm{BC}$ survivors were diagnosed at stage II $(\mathrm{n}=25)$. At baseline, there is no statistical difference between the two groups in terms of ethnicity, marital status, number of children, menopausal status and financial status. However, there is significant different between groups in terms of the educational level and current occupational status, whereby more women in the HC work full time, and there were higher educated as well. More than $50 \%$ of participants self perceived that they participated in 1 to 2 days light exercises per week, not amounting to the recommended dosage.

\subsection{Physical Activity of Women (IPAQ)}

The mean MET values for healthy control (HC) group was $1317.1 \pm 1116$ minutes/week, but only at a low $371.9 \pm 273$ METs for BC participants. As per IPAQ guide, the METS are far lower than the low-intensities level $(<600 \mathrm{MET}-\mathrm{min} /$ week), or the moderate-intensity level (>600 MET-min/week) or vigorous intensity activities (at least $3000 \mathrm{MET}-\mathrm{min} /$ week). There is a significant different between groups in the level of physical activity (Table 2). Based on these guide, 91.1\% of HC subjects engaged in low $(31.1 \%)$ to moderate $(60 \%)$ level of physical activity. All $(100 \%)$ of BC patients engaged in low $(84.3 \%)$ to moderate $(15.7 \%)$ level of physical activity, with no person engaging in vigorous level.

\subsection{Exercise Self-Efficacy in Multiethnic Women-between Groups and within Group}

Table 3(a) shows between groups analyses, whereby significant differences were found in two subscales [situational, $\mathrm{p}=0.04$, and competing demands, $\mathrm{p}=0.01$ ) and in the total self-efficacy scale $(p=0.03)$. The mean scores of the cancer survivors were higher than the healthy adults, indicating a higher level of confidence to engage in regular exercise (than healthy adults). However, across the subscale, situational/interpersonal factor recorded the lowest mean value amongst survivors -suggesting a possible social barrier to exercise engagement, related to the breast cancer. In terms of ethnicity, there is no significant different across the three ethnic groups for level of activity (Table 3(b)).

\subsection{Barriers to Physical Activity: Case (51) vs. Control (47)}

Table 4 is a list of top ten barriers (from a list of 22 barriers) reported by a group of Malaysian women with breast cancer $(n=51)$ and without breast cancer $(n=45)$. Both cases and control rated highly for "lack of time and too many household chores". A contrast between the groups, is that these healthy control reported 'being lazy and too much office work to do" as key barriers. In our survey, the $\mathrm{HC}$ group identified more barriers to physical activity compared to $\mathrm{BC}$ patients $[\mathrm{HC}$ mean $=6 \pm 3$ vs. $\mathrm{BC}$ mean $=4 \pm 3 ; \mathrm{U}=686, \mathrm{p}=0.001]$, which suggest 
Table 1. Characteristics of breast cancer survivors and healthy controls.

\begin{tabular}{|c|c|c|c|c|}
\hline Characteristic & All $(\mathrm{n}=96)$ & Healthy Subjects $(\mathrm{n}=45)$ & Breast Cancer Survivors $(\mathrm{n}=51)$ & \\
\hline \multirow[t]{2}{*}{ Age (Mean \pm SD) Length of Survivorship } & $49.12 \pm 8.86$ & $48.11 \pm 9.50$ & $50.01 \pm 8.2532 .78 \pm 16.65$ & \\
\hline & \multicolumn{3}{|c|}{ (n) $\%$} & * p \\
\hline \multicolumn{5}{|l|}{ Ethnicity } \\
\hline Chinese & (43) 44.8 & (21) 46.7 & (22) 43.1 & 0.86 \\
\hline Indian & (26) 27.1 & (11) 24.4 & (15) 29.4 & \\
\hline Malay & (27) 28.1 & (13) 28.9 & (14) 27.5 & \\
\hline \multicolumn{5}{|l|}{ Present Marital Status } \\
\hline Single & (15) 15.6 & (7) 15.6 & (8) 15.7 & 0.99 \\
\hline Married & (77) 80.2 & (36) 80.0 & (41) 80.4 & \\
\hline Widowed/Divorced & (4) 4.2 & (2) 4.4 & (2) 3.9 & \\
\hline \multicolumn{5}{|l|}{ Number of Children } \\
\hline None & (20) 20.8 & (11) 24.4 & (9) 17.6 & 0.65 \\
\hline Less than 2 & (36) 37.5 & (18) 40.0 & (18) 35.3 & \\
\hline 3 to 5 & (36) 37.5 & (14) 31.1 & (22) 43.1 & \\
\hline More than 5 & (4) 4.2 & (2) 4.4 & (2) 3.9 & \\
\hline \multicolumn{5}{|l|}{ Educational } \\
\hline No Formal Education & (1) 1.0 & (1) 2.2 & (0) 0 & 0.003 \\
\hline Primary & (6) 6.3 & (2) 4.4 & (4) 7.8 & \\
\hline Secondary & (41) 42.7 & (11) 24.4 & (30) 58.8 & \\
\hline College/University & (48) 50.1 & (31) 68.8 & (17) 32.3 & \\
\hline \multicolumn{5}{|l|}{ Menopausal Status } \\
\hline Pre-Menopause & (51) 53.1 & (26) 57.8 & (25) 49 & \\
\hline Post-Menopause & (45) 46.9 & (19) 42.2 & (26) 51 & 0.39 \\
\hline \multicolumn{5}{|l|}{ Status of Occupation } \\
\hline Full-Time & (49) 51.0 & (30) 66.7 & (19) 37.3 & \\
\hline Unemployed/Retired & (20) 20.8 & (3) 6.7 & (17) 33.3 & 0.000 \\
\hline Part-Time & (7) 7.3 & (6) 13.3 & (1) 2.0 & \\
\hline Homemaker & (20) 20.8 & (6) 13.3 & (14) 27.5 & \\
\hline \multicolumn{5}{|l|}{ Financial Status } \\
\hline$<$ USD $166-333$ & (19) 19.8 & (10) 22.2 & (9) 17.6 & \\
\hline USD $334-1000$ & (30) 31.3 & (13) 28.9 & (17) 33.3 & \\
\hline USD $1001->1666$ & (47) 49.0 & (22) 48.8 & (25) 48.0 & 0.381 \\
\hline \multicolumn{5}{|l|}{ Stage } \\
\hline 0 & - & - & (4) 7.8 & \\
\hline I - III & - & - & (42) 82.4 & \\
\hline Don't Know & - & - & (5) 9.8 & \\
\hline Type & - & & & \\
\hline Ductal Carcinoma in Situ & - & - & (8) 15.7 & \\
\hline Invasive Carcinoma & & - & (5) 9.8 & \\
\hline I Don’t Know & & & (38) 74.5 & \\
\hline
\end{tabular}

${ }^{*}$ Chi-square test or fisher exact test ( 2 tailed) were used. Differences between case and control are not significant (except for education and occupation), among $\mathrm{BC}$ and $\mathrm{HC}$ groups, $\mathrm{p}<0.001$.

Table 2. Physical activity in case (breast cancer survivors) and control (healthy subjects).

\begin{tabular}{|c|c|c|c|c|c|c|c|}
\hline & \multicolumn{3}{|c|}{ Breast cancer survivors $(\mathrm{n}=51)$} & \multicolumn{3}{|c|}{ Healthy subjects $(\mathrm{n}=45)$} & \multirow{2}{*}{$\frac{\text { Mann-Whitney }}{\text { p-value }}$} \\
\hline & Total & Median & IQR & Sum & Mean & SD & \\
\hline IPAQ-Vigorous $(8 \times$ days $\times$ minutes $)$ & 788.3 & 15.46 & 51.38 & 7375.6 & 163.90 & 304.61 & $0.006^{*}$ \\
\hline IPAQ-Moderate $(4 \times$ days $\times$ minutes $)$ & 3177.2 & 62.3 & 132.84 & 15921.4 & 353.81 & 387.66 & $0.000^{*}$ \\
\hline IPAQ-Walking $(3.3 \times$ days $\times$ minutes $)$ & 15004.3 & 294.2 & 274.99 & 35973.8 & 799.42 & 890.47 & $0.007^{*}$ \\
\hline Total $=$ Vig + Mod + Walking & 18969.78 & 371.96 & 273.10 & 59270.79 & 1317.13 & 1116.01 & $0.000^{*}$ \\
\hline
\end{tabular}

\footnotetext{
"Mann-Whitney U Test, $\mathrm{p}<0.01$; mins $=$ minutes.
} 
Table 3. (a) Exercise self-efficacy in breast cancer survivors and control; (b) Mean/median on exercise self-efficacy (comparing ethnicity within group).

(a)

\begin{tabular}{|c|c|c|c|c|c|}
\hline Exercise self-efficacy Sub scales and total scale & Control $(n=45)$ Case $(n=51)$ & $\mathrm{n}$ & Mean & SD & P value \\
\hline \multirow{2}{*}{ Situational/Interpersonal } & Control (healthy) & 45 & 28.2 & 17.0 & $0.04^{*}$ \\
\hline & Case (survivors) & 51 & 35.7 & 19.3 & \\
\hline \multirow{2}{*}{ Competing demand } & Control (healthy) & 45 & 34.4 & 17.8 & $0.01^{*}$ \\
\hline & Case (survivors) & 51 & 43.13 & 16.3 & \\
\hline \multirow{2}{*}{ Internal feelings } & Control (healthy) & 45 & 31.1 & 18.8 & 0.12 \\
\hline & Case (survivors) & 51 & 36.7 & 15.2 & \\
\hline \multirow{2}{*}{ Total exercise self-efficacy } & Control (healthy) & 45 & 31.0 & 16.3 & $0.03^{*}$ \\
\hline & Case (survivors) & 51 & 38.2 & 15.3 & \\
\hline
\end{tabular}

Control $=$ Healthy woman; Case $=$ Breast cancer patients; ${ }^{*}=$ Significant at $\mathrm{p}<0.05$.

(b)

\begin{tabular}{|c|c|c|c|c|c|c|c|c|c|c|}
\hline & \multicolumn{5}{|c|}{ Control $(\mathrm{n}=45)$} & \multicolumn{5}{|c|}{ Case $(\mathrm{n}=51)$} \\
\hline & \multicolumn{2}{|c|}{ Mean + SD } & \multicolumn{2}{|c|}{ Median + IQR } & $\mathrm{p}$ & \multicolumn{2}{|c|}{ Mean + SD } & \multicolumn{2}{|c|}{ Median + IQR } & $\mathrm{p}$ \\
\hline Chinese & 25.3 & 20.6 & & & \multirow{3}{*}{0.50} & 37.5 & 22.0 & 36.7 & 29.2 & \multirow{3}{*}{0.27} \\
\hline Indian & 28.6 & 14.4 & & & & 38.2 & 17.0 & 36.1 & 13.3 & \\
\hline Malay & 22.4 & 11.9 & & & & 30.2 & 17.5 & 27.5 & 22.9 & \\
\hline \multicolumn{11}{|c|}{ Competing Demand } \\
\hline Chinese & 34.3 & 18.3 & 34.0 & 27.0 & \multirow{3}{*}{0.41} & 45.6 & 17.0 & & & \multirow{3}{*}{0.60} \\
\hline Indian & 30.3 & 20.2 & 26.0 & 22.0 & & 42.5 & 19.2 & & & \\
\hline Malay & 38.1 & 15.4 & 38.0 & 24.0 & & 39.9 & 12.1 & & & \\
\hline \multicolumn{11}{|c|}{ Internal Feelings } \\
\hline Chinese & 28.0 & 18.3 & & & \multirow{3}{*}{0.54} & 38.3 & 16.2 & & & \multirow{3}{*}{0.81} \\
\hline Indian & 31.7 & 20.1 & & & & 35.4 & 16.6 & & & \\
\hline Malay & 35.5 & 19.2 & & & & 35.6 & 12.9 & & & \\
\hline \multicolumn{11}{|c|}{ Total Efficacy } \\
\hline Chinese & 28.9 & 17.5 & 27.2 & 29.4 & \multirow{3}{*}{0.46} & 40.1 & 16.9 & 38.1 & 20.4 & \multirow{3}{*}{0.39} \\
\hline Indian & 30.2 & 17.3 & 27.2 & 24.4 & & 38.3 & 16.0 & 38.4 & 16.1 & \\
\hline Malay & 35.2 & 14.0 & 37.2 & 28.6 & & 35.0 & 12.4 & 32.2 & 13.9 & \\
\hline
\end{tabular}

that these healthy women may have no "life-threatening" teachable moments (experienced by cancer survivors) to spur them to adopt physical activity.

Lack of time was found as the number one barrier, by all ethnic group in both survivors and healthy adults. Environmental barriers especially weather and traffic were also rated highly, which is expected in the busy city where the study was conducted. The Chinese and Indian rated lack of time and job commitments as the leading barriers because they were predominantly working. The Malay ethnic group rated having no social companion, bodily ache and knowledge barrier (i.e. do not know evidence on exercise and do not know how to exercise) as their key barriers.

\subsection{Video Media for Cancer Control on Physical Activity}

HC perceived that women with breast cancer are not suitable to engage in any type of physical activity neither during nor after treatment. Only $44.4 \%$ of the HC subjects agreed that exercise can reduce the risk of breast cancer recurrence prior to watching the video. Amongst 
women with breast cancer, about $44.7 \%$ of the subjects disagreed that they can do moderate exercise during treatment and, a high $71 \%$ disagreed that women with breast cancer can do vigorous exercise during treatment. After viewing the video, about $99 \%$ of the participants agreed to the minimum recommended duration of physical activity for adults is 30 minutes per day, $81.3 \%$ perceived that minimum recommended frequency of physiccal activity for adult is 3 to 5 days and $85.4 \%$ identifies adult should engage in moderate physical activity. 93.3\% of $\mathrm{HC}$ group agreed that active lifestyle can reduce the risk of breast cancer recurrence while 2.2 disagreed with this notion and $4.4 \%$ were still not convinced. Overall, the subjects perceived that the video is effective in influencing cancer survivors to engage in more active lifestyle $(\mathrm{M}=7.1, \mathrm{SD}=1.53, \mathrm{p}<0.01)$. Table 5 show that at post video, the knowledge improves as more participants become aware that women with breast cancer can do moderate exercises during treatment.

\section{DISCUSSION}

Investigations of the determinants of physical activity motivation and behaviour can help identify the shared and unique correlates of motivation that predict the participation in regular physical activity between cancer survivors and healthy population [38]. This survey found that survivors reported less barriers compared to healthy adults and their exercise self efficacy was higher than the healthy adults. The findings suggest that non-cancer subjects have more excuses for exercise and reported more barriers. Self-efficacy is the belief and conviction that one can successfully perform the exercise, and higher efficacy predicts better adoption of exercise behaviors. Intervention to redesign lifestyle of survivors as part of rehabilitation and cancer control strategy should optimize these teachable moments after a cancer diagnosis. McBride et al. [39]) explained "teachable moments" as the naturally occurring life transitions or health events

Table 4. Top barriers to physical activity engagement: case-control.

\begin{tabular}{|c|c|c|c|c|c|c|c|c|}
\hline \multirow[b]{2}{*}{ Top 10 Barriers (from a list of 22) } & \multicolumn{4}{|c|}{ BC Survivors $($ Case $=51)$} & \multicolumn{4}{|c|}{ Healthy Women (Control = 45) } \\
\hline & All (51) & $\begin{array}{l}\text { Chinese } \\
(\mathrm{n}=22)\end{array}$ & $\begin{array}{l}\text { Indian } \\
(\mathrm{n}=15)\end{array}$ & $\begin{array}{c}\text { Malay } \\
(\mathrm{n}=14)\end{array}$ & $\begin{array}{c}\text { All } \\
(45)\end{array}$ & $\begin{array}{l}\text { Chinese } \\
(\mathrm{n}=21)\end{array}$ & $\begin{array}{l}\text { Indian } \\
(\mathrm{n}=11)\end{array}$ & $\begin{array}{c}\text { Malay } \\
(\mathrm{n}=13)\end{array}$ \\
\hline & Yes $(\%)$ & Yes $(\%)$ & Yes $(\%)$ & Yes $(\%)$ & Yes $(\%)$ & Yes $(\%)$ & Yes $(\%)$ & Yes $(\%)$ \\
\hline I don't have time & 58.8 & 68.2 & 60.0 & 42.9 & 51.1 & 33.3 & 72.7 & 61.5 \\
\hline Too many household chores & 51.0 & 68.2 & 33.3 & 42.9 & 48.9 & 23.8 & 81.8 & 61.5 \\
\hline I don't have friends to exercise & 33.3 & 27.3 & 20 & 57.1 & 37.8 & 38.1 & 36.4 & 38.5 \\
\hline The weather and traffic puts me off & 31.3 & 50.0 & 13.3 & 28.6 & 30.0 & 21.4 & 31.9 & 42.4 \\
\hline I have bodily ache and pain & 27.5 & 22.7 & 13.3 & 50.5 & 40.0 & 38.1 & 63.6 & 23.1 \\
\hline I am too lazy & 27.5 & 31.8 & 26.7 & 31.4 & 51.1 & 47.6 & 45.5 & 61.5 \\
\hline I have too much office work to do & 23.5 & 22.7 & 26.7 & 21.4 & 51.1 & 33.3 & 81.8 & 43.8 \\
\hline No proper place to exercise & 15.7 & 9.1 & 13.3 & 28.6 & 26.7 & 23.8 & 36.4 & 23.1 \\
\hline Don't know how to exercise & 15.7 & 9.1 & 6.7 & 35.7 & 13.3 & 14.3 & 9.1 & 15.4 \\
\hline I wasn't even thinking of exercise & 11.8 & 0 & 20.0 & 21.4 & 17.8 & 19.0 & 27.3 & 7.7 \\
\hline
\end{tabular}

Table 5. Correlations between Pre and Post video viewing (can survivors do moderate exercise).

\begin{tabular}{|c|c|c|c|c|c|c|}
\hline Prevideo & \multicolumn{6}{|c|}{ Post-video during treatment, women with cancer can do moderate exercise } \\
\hline \multirow{7}{*}{$\begin{array}{l}\text { During treatment, women } \\
\text { with breast cancer } \\
\text { can do } \\
\text { moderate } \\
\text { exercise }\end{array}$} & & & Agree & Disagree & Don't know & TOTAL \\
\hline & \multirow{2}{*}{ Agree } & $\mathrm{n}$ & 60 & 0 & 0 & 60 \\
\hline & & $\%$ & $100 \%$ & $0 \%$ & $0 \%$ & $100 \%$ \\
\hline & \multirow{2}{*}{ Disagree } & $\mathrm{n}$ & 12 & 2 & 0 & 14 \\
\hline & & $\%$ & $85.7 \%$ & $14.3 \%$ & $0 \%$ & $100 \%$ \\
\hline & \multirow{2}{*}{ Don't know } & $\mathrm{n}$ & 18 & 1 & 3 & 22 \\
\hline & & $\%$ & $81.8 \%$ & $4.5 \%$ & $13.6 \%$ & $100 \%$ \\
\hline
\end{tabular}

[Fisher's Exact Test, $\mathrm{p}=0.001$ (2-tailed)]. At post video, more participants become aware and their disagreement that women with breast cancer cannot do moderate exercise reduces and even those who rated they do not know, have reduces as well. 
that have the potential to motivate individuals to spontaneously adopt risk-reducing or health-protective behaviors. Thus, regardless of age and ethnic, a key focus for rehabilitation therapists is to design group physical activity that can further enhance exercise self efficacy via modelling and motivation via supportive and enjoyable physical activity. As education may play an important role in health promotion and uptake of exercise, oncology Occupational therapists must gauged individual barriers, and determine the pre-contemplations stage using the stages of change model [40], in order to mobilised people towards health via physical activity engagement.

With the post-video survey, our study showed more participants become aware of physical activity guides at post video viewing, and their disagreement that women with breast cancer cannot do moderate exercise reduces and even those who rated they do not know have reduces. However, across group, all rated time as a barrier to exercise. Despite strong evidence suggesting that regular physical activity can protect against breast cancer recurrence [41,42], only $23.5 \%$ of breast cancer survivors engage in the recommended level of physical activity defined as 150 minutes per week of moderate-intensity physical activity. Similar result was observed among US cancer survivors whereby approximately $30 \%$ of cancer survivors met the physical activity guidelines [43]. A qualifying clause was even added by these women who suggested that although moderate activity may be feasible, women should never exert themselves during treatment. These findings suggest that structured program is needed to guide patients towards being better informed and for adopting a healthy lifestyle since behaviour change is difficult across the globe.

Cancer treatment has long been cited as a potential barrier of exercise involvement among women with breast cancer. A study from Australia found that only $13 \%$ of women on chemotherapy treatment were physically active [44]. In a study of 130 colorectal carcinoma survivors, Courneya and Friedenreich reported that treatment had a significant negative effect on physical activity participation levels which did not recover completely post treatment and that decreased physical activity levels are associated with a worse quality of life [45]. Thus, more noncancerous controls $(68.9 \%)$ engaged in moderate-intensity physical activity as compared with breast cancer patients. This result is differ from US Behavioural Risk Factor Surveillance System revealed that only $27 \%$ of healthy US women met the current physical activity recommendation [46]. However, this result is subject to a possible selection bias due to the low response rate among healthy volunteers.

Although cancer treatment affects the engagement and reengagement of physical activity levels, studies had shown that even women undergoing intensive therapy for breast cancer are able to be physically active during and following treatment [47]. The cancer survivors were more predictable by the exercise self-efficacy as a contemplating factor to active lifestyle. Exercise self-efficacy is higher among BC survivors but still considered relatively low as compared to finding on Korean adults with chronic diseases [37]. This explains the low level of physical activity engagement in this study. Both groups perceived the situational/interpersonal factor as the lowest exercise self-efficacy factor. The similarity may result from collectivism-orientated [48] culture of Asia countries where the external sub-factor related to other persons/organisational settings can markedly affect the perception of exercise self-efficacy and participation in physical activity for an individual. In relation to collectivism culture, lack-of-time factor was identified as a key barrier to regular physical activity in both healthy control and breast cancer population, as a result of domestic commitments. Similar result was also observed in other published studies focusing on nondisabled adults [49, 50].

Video on promoting active lifestyle was perceived as an effective tool to encourage participation in physical activity amongst cancer survivors. Participants reported learning about the benefits of regular exercise and an increase awareness of the significant role of physical activity in lowering cancer recurrence. As it is generally difficult to get people to adhere to a regular exercise, the message that one can accumulate short bouts of 10 minutes exercise needs to be emphasised aggressively. As an example, the National Heart Foundation of Australia evaluated the effectiveness of promoting physical activity through paid national television advertisements, public service announcements on the radio, distribution of a professional paper, posters, leaflets and stickers, T-shirts, publicity tours by experts and two nationally broadcast television dramas [51]. Face-to-face interviews were conducted with 2500 people before and after each campaign, found statistically significant differences in message awareness $(46 \%$ vs. $71 \%$ in $1990 ; 63 \%$ vs. $74 \%$ in 1991). In 1990, there were significant increases in walking, particularly among older people, and including, increased in intentions to exercise. Thus, public message must be carefully selected and targeted at personal and societal level, with organisational input and support.

This small study generated insightful understanding of physical activity in cancer survivors and in healthy controls, despite some methodological limitations. The findings of this study are descriptive and do not infer causality. All data were obtained from a self-reported survey whereby participants can be subjected to recall bias. Further longitudinal studies could provide insights on how these barriers factors function in respect to each other as moderating variables and provide evidence on 
directions of causality.

\section{CONCLUSION}

While awareness of maintaining healthy lifestyle has increased, most survivors in this survey were not aware that physical activity can reduce cancer recurrence, and for cancer control. Public health messages on the importance of physical activity must be broadcasted during the "teachable moments" after a traumatic awakening from a cancer diagnosis. This opportune effort should be utilized maximally to ensure cancer survivors engage and reengage a low risk lifestyle, by increasing activity in their daily routines. Positive lifestyle changes can help women with a breast cancer diagnosis to live longer and enhanced quality of life. 'Staying active' is an effective cancer control message to be promoted in the model of cancer survivorship care, with culturally relevant approaches to address physical inactivity.

\section{REFERENCES}

[1] Booth, F.W., et al. (2000) Waging war on modern chronic diseases: Primary prevention through exercise biology. Journal of Applied Physiology, 88, 774-787.

[2] Helmrich, S.P., et al. (1991) Physical activity and reduced occurrence of non-insulin-dependent diabetes mellitus. New England Journal of Medicine, 325, 147-152. doi:10.1056/NEJM199107183250302

[3] Pietro, L.D., Dziura. J. and Blair, S.N. (2004) Estimated change in physical activity level (pal) and prediction of 5 -year weight change in men: The aerobics center longitudinal study. International Journal of Obesity, 28, 15411547. doi:10.1038/sj.ijo.0802821

[4] Greendale, G.A., et al. (1995) Lifetime leisure exercise and osteoporosis. The rancho bernardo study. American Journal of Epidemiology, 141, 951-959.

[5] Fletcher, G.F., et al. (1996) Statement on exercise: Benefits and recommendations for physical activity programs for all Americans: A statement for health professionals by the committee on exercise and cardiac rehabilitation of the council on clinical cardiology, American heart association. Circulation, 94, 857-862. doi:10.1161/01.CIR.94.4.857

[6] Schwartz, A. (2008) Physical activity. Seminars in Oncology Nursing, 24, 164-170. doi:10.1016/j.soncn.2008.05.004

[7] Heineman, E.F., et al. (1994) Increased risk of colorectal cancer among smokers: Results of a 26-year follow-up of US veterans and a review. International Journal of Cancer, 59, 728-738. doi:10.1002/ijc.2910590603

[8] Bianchini, F., Kaaks, R. and Vainio, H. (2002) Weight control and physical activity in cancer prevention. Obesity Reviews: An Official Journal of the International Association for the Study of Obesity, 3, 5-8.

[9] Voskuil, D.W., et al. (2007) Physical activity and endometrial cancer risk, a systematic review of current evi- dence. Cancer Epidemiology Biomarkers \& Prevention, 16, 639-648. doi:10.1158/1055-9965.EPI-06-0742

[10] Lee, I.M., Sesso, H.D. and Paffenbarger, R.S. (1999) Physical activity and risk of lung cancer. International Journal of Epidemiology, 28, 620-625. doi:10.1093/ije/28.4.620

[11] Hsing, A.W., et al. (1994) Occupation, physical activity, and risk of prostate cancer in Shanghai, People's Republic of China. Cancer Causes and Control, 5, 136-140. doi:10.1007/BF01830259

[12] Kruk, J. and Aboul-Enein, H. (2006) Physical activity in the prevention of cancer. Asian Pacific Journal of Cancer Prevention, 7, 11-21.

[13] McTiernan, A. (2004) Physical activity after cancer: Physiologic outcomes. Cancer Investigation, 22, 68-81. doi:10.1081/CNV-120027581

[14] Thune, I., et al. (1997) Physical activity and the risk of breast cancer. New England Journal of Medicine, 336, 1269-1275. doi:10.1056/NEJM199705013361801

[15] Friedenreich, C.M., et al. (2012) Inflammatory marker changes in a yearlong randomized exercise intervention trial among postmenopausal women. Cancer Prevention Research, 5, 98-108.

[16] Chlebowski, R.T., Aiello, E. and McTiernan, A. (2002) Weight loss in breast cancer patient management. Journal of Clinical Oncology, 20, 1128-1143. doi:10.1200/JCO.20.4.1128

[17] Daling, J.R., et al. (2001) Relation of body mass index to tumor markers and survival among young women with invasive ductal breast carcinoma. Cancer, 92, 720-729. doi:10.1002/1097-0142(20010815)92:4<720::AID-CNC R1375>3.0.CO;2-T

[18] Kroenke, C., et al. (2005) Weight, weight gain, and survival after breast cancer diagnosis. Journal of Clinical Oncology, 23, 1370-1378. doi:10.1200/JCO.2005.01.079

[19] Suijkerbuijk, K.P.M., et al. (2006) Physical activity in relation to mammographic density in the dutch prospectEuropean prospective investigation into cancer and nutrition cohort. Cancer Epidemiology Biomarkers \& Prevention, 15, 456-460. doi:10.1158/1055-9965.EPI-05-0569

[20] Holmes, M.D., et al. (2004) Physical activity and survival after breast cancer diagnosis. AACR Meeting Abstracts, 2004, 336 .

[21] Monninkhof, E.M., et al. (2007) Physical activity and breast cancer: A systematic review. Epidemiology, 18, 137-157. doi:10.1097/01.ede.0000251167.75581.98

[22] World Health Organization (2003) Health and development through physical activity and sport. World Health Organization, Geneva.

[23] Piro, F.N., Nœss, Ø. and Claussen, B. (2006) Physical activity among elderly people in a city population: The influence of neighbourhood level violence and self perceived safety. Journal of Epidemiology and Community Health, 60, 626-632. doi:10.1136/jech.2005.042697

[24] Brownson, R.C., Boehmer, T.K. and Luke, D.A. (2005) Declining rates of physical activity in the United States: What are the contributors? Annual Review of Public Health, 26, 421-443. 
doi:10.1146/annurev.publhealth.26.021304.144437

[25] Wendel-Vos, W., et al. (2007) Potential environmental determinants of physical activity in adults: A systematic review. Obesity Reviews, 8, 425-440. doi:10.1111/j.1467-789X.2007.00370.x

[26] Huston, S.L., et al. (2003) Neighborhood environment, access to places for activity, and leisure-time physical activity in a diverse North Carolina population. American Journal of Health Promotion, 18, 58-69. doi:10.4278/0890-1171-18.1.58

[27] Kahn, E.B., et al. (2002) The effectiveness of interventions to increase physical activity: A systematic review. American Journal of Preventive Medicine, 22, 73-107. doi:10.1016/S0749-3797(02)00434-8

[28] Institute for Public Health (2006) The third national health and morbidity survey. Physical Activity, Ministry of Health, Kuala Lumpur. http://www.nih.gov.my

[29] World Health Organisation (2004) Global strategy on diet, physical activity and health. World Health Organisation, Geneva.

[30] Stewart, B.W. and Paul Kleihues, P. (2003) World cancer report. World Health Organization, Lyon.

[31] Demark-Wahnefried, W., et al. (2001) Changes in weight, body composition, and factors influencing energy balance among premenopausal breast cancer patients receiving adjuvant chemotherapy. Journal of Clinical Oncology, 19, 2381-2389.

[32] Loh, S.Y., et al. (2007) Perceived barriers to self management in Malaysian women. Asia Pacific Journal of Public Health, 19, 52-57. doi: $10.1177 / 101053950701900309$

[33] Loh, S.Y., et al. (2009) Targeting health disparity in breast cancer: Insights into women's knowledge of their cancer profile in Malaysia. Asian Pacific Journal of Cancer Prevention, 10, 631-636.

[34] Loh, S.Y., et al. (2011) Does a self management intervention lower distress in woman diagnosed with breast cancer? Japanese Psychological Research, 54, 159-169.

[35] Craig, C., et al. (2003) International physical activity questionnaire: 12-country reliability and validity. Medicine \& Science in Sports \& Exercise, 35, 1381-1395. doi:10.1249/01.MSS.0000078924.61453.FB

[36] Bandura, A. (2006) Guide for constructing self-efficacy scales, in self-efficacy beliefs of adolescents. In: Pajares, F. and Urdan, T., Eds., Adolescence and Education, Information Age Publishing, Greenwich, 301-337.

[37] Shin, Y., Jang, H. and Pender, N.J. (2001) Psychometric evaluation of the exercise self-efficacy scale among Korean adults with chronic diseases. Research in Nursing \& Health, 24, 68-76.

[38] Pinto, B.M., et al. (2011) Physical activity motivation and cancer survivorship. Recent Results in Cancer Research,
186, 367-387.

[39] McBride, C.M., Emmons, K.M. and Lipkus, I.M. (2003) Understanding the potential of teachable moments: The case of smoking cessation. Health Education Research, 18, 156-170. doi:10.1093/her/18.2.156

[40] Prochaska, J.O., DiClemente, C.C. and Norcross, J.C. (1992) In search of how people change. American Psychologist, 47, 1102-1114. doi:10.1037/0003-066X.47.9.1102

[41] Thune, I. and Ferberg, A. (2001) Physical activity and cancer risk: Dose-response and cancer, all sites and site specific. Medicine \& Science in Sports \& Exercise, 33, S530-S550.

[42] Kamarudin, R., Shah, S.A. and Hidayah, N. (2006) Lifestyle factors and breast cancer: A case-control study in Kuala Lumpur, Malaysia. Asia Pacific Journal of Cancer Prevention, 7, 51-54.

[43] Bellizzi, K.M., et al. (2005) Health behaviors of cancer survivors: Examining opportunities for cancer control intervention. Journal of Clinical Oncology, 23, 8884-8893. doi:10.1200/JCO.2005.02.2343

[44] Milne, H.M., et al. (2007) Association between physical activity and quality of life among western Australian breast cancer survivors. Psycho-Oncology, 16, 1059-1068. doi:10.1002/pon.1211

[45] Courney, K.S. and Friedenreich, C.M. (1997) Relationship between exercise pattern across the cancer experience and current quality of life in colorectal cancer survivors. Journal of Alternative and Complementary Medicine, 3, 215-226.

[46] Brownson, R.C., et al. (2000) Measuring physical activity with the behavioural risk factor surveillance system. Medicine \& Science in Sports \& Exercise, 32, 1913-1918. doi:10.1097/00005768-200011000-00015

[47] Courneya, K.S. (2001) Exercise interventions during cancer treatment: Biopsychosocial outcomes. Exercise and Sport Sciences Reviews, 29, 60-64. doi:10.1097/00003677-200104000-00004

[48] Lee, S.W. (1987) Affection of Korean interpersonal relationship. Modern Society, 7, 146-159.

[49] Johnson, C.A., et al. (1990) Perceived barriers to exercise and weight control practices in community women. Women \& Health, 16, 177-191. doi:10.1300/J013v16n03 10

[50] Nelson, J.P. (1991) Perceived health, self-esteem, health habits, and perceived benefits and barriers to exercise in women who have and who have not experienced stage I breast cancer. Oncology Nursing Forum, 18, 1191-1197.

[51] Owen, N., et al. (1995) Serial mass-media campaigns to promote physical activity: Reinforcing or redundant? American Journal of Public Health, 85, 244-248. doi:10.2105/AJPH.85.2.244 